\title{
MOMMSEN, Hans, GRIEGER, Manfred, Das Volkswagenwerk und seine Arbeiter im Dritten Reich
}

Hervé Joly

\section{OpenEdition}

\section{Journals}

Édition électronique

URL : http://journals.openedition.org/ifha/1426

DOI : $10.4000 /$ ifha. 1426

ISSN : 2198-8943

Éditeur

IFRA - Institut franco-allemand (sciences historiques et sociales)

Référence électronique

Hervé Joly, " MOMMSEN, Hans, GRIEGER, Manfred, Das Volkswagenwerk und seine Arbeiter im Dritten Reich », Revue de l'IFHA [En ligne], Date de recension, mis en ligne le 01 janvier 1999, consulté le 22 septembre 2020. URL : http://journals.openedition.org/ifha/1426 ; DOI : https://doi.org/10.4000/ifha. 1426

Ce document a été généré automatiquement le 22 septembre 2020.

(C)IFHA 


\title{
MOMMSEN, Hans, GRIEGER, Manfred, Das Volkswagenwerk und seine Arbeiter im Dritten Reich
}

\author{
Hervé Joly
}

1 Ce livre représente une impressionnante somme comme seule l'organisation universitaire allemande peut permettre d'en produire. Derrière le professeur Hans MOMMSEN (Bochum), avec son assistant Manfred GRIEGER promu au rang de coauteur, c'est, comme l'indique le maitre d'œuvre du projet, toute une équipe de collaborateurs scientifiques et d'étudiants qui s'est répartie cet énorme travail étalé sur près de 10 ans. Les grandes lacunes des archives de l'entreprise Volkswagen sur la période nazie - qui, contrairement à ce qu'indique un article récent du Monde diplomatique (janvier 1998) entretenant de fausses polémiques, ne sont pas dues à un barrage de la direction de l'entreprise, au contraire associée au projet à l'initiative de son patron de l'époque Carl Hahn, mais à des destructions antérieures - ont obligé à recourir à de multiples sources externes. À ce sujet, il convient de regretter le refus de la société Peugeot, placée sous la tutelle technique de Volkswagen en 1943, d'ouvrir ses archives aux auteurs. Ce livre constitue une véritable "histoire totale« de l'entreprise Volkswagen sous le nazisme, des premiers projets de "voitures populaires« dès 1933 jusqu'à la mise sous tutelle par les Alliés en 1945. Si les premiers chapitres relèvent surtout d'une histoire économique, avec l'évocation des réticences de l'industrie automobile privée à soutenir le projet de Ferdinand Porsche, puis politique, avec sa prise en main par le Deutsche Arbeitsfront, le reste du livre donne une place importante à l'histoire sociale du personnel. Il n'est rapidement plus question de voiture populaire car sa production et sa commercialisation s'arrêtent avant même d'avoir commencé avec le début de la guerre. La nouvelle usine de Wolfsburg se transforme alors en un producteur polyvalent de matériel militaire. Les auteurs font cependant justice de la légende selon laquelle la véritable finalité militaire aurait été prévue dès le départ. Ils insistent au contraire sur le caractère particulièrement improvisé et désordonné de la politique menée par les dirigeants de l'entreprise, à la recherche permanente de contrats multiples pour justifier des investissements importants. Volkswagen produit ainsi non seulement des 
modèles transformés pour la Wehrmacht de sa Coccinelle, mais aussi des fuselages d'avions, des mines, des fusées, etc. Confrontée, dans le contexte de la guerre, à des difficultés croissantes de recrutement d'un personnel allemand qualifié, l'entreprise fait appel à des mains-d'œuvre étrangères successives, dont la composante initialement volontaire (Américains d'origine allemande pour l'encadrement technique, Italiens pour la construction) s'avère rapidement insuffisante. Elle utilise alors massivement une main-d'œuvre forcée, russe puis française notamment, avant de s'associer à la machine de terreur nazie, avec l'implantation d'une annexe du camp de concentration de Neuengamme à côté de l'usine. Si ce sont surtout les gardiens SS qui sont responsables des mauvais traitements subis par les détenus, la direction de l'usine a recours à leur force de travail sans grands scrupules. L'image de Ferdinand Porsche, en particulier, en ressort sérieusement écornée: son »apolitisme« prétendu cache mal une grande habileté à tirer son épingle du jeu dans la polyarchie nazie. Même le technicien génial n'en sort pas indemne: l'élaboration de sa "Coccinelle« connaît certains cafouillages et, ensuite, ses prototypes de chars s'avèrent inadaptés. Au total, le livre présente un bilan nuancé mais sans complaisance. La richesse iconographique mérite également d'être soulignée. Il faut cependant regretter que la forme se ressente d'une écriture à plusieurs mains. Le souci d'exhaustivité l'emporte sur la lisibilité. Les principales conclusions ressortent mal. Une version plus synthétique serait indispensable, en particulier pour le lecteur français. 